3 Porter KM. Neck sprains after car accidents. BMF 1989;298:973-4.

4 Maimaris C. Neck sprains after car accidents. $B M F$ 1989;299:123.

5 Van Meydam K, Sehlen S, Schlenkhoff D, Kiricuta JC, Beyer HK. Kernspintomographische Befunde beim Halswirbelsäulentrauma. Fortschr Roengenstr 1986;145 657-60.

6 Yarnell PR, Rossie GV. Minor whiplash head injury with major debilitation. Brain Inj 1988;2/3:255-8.

7 Pearce JMS. Whiplash injury, fact or fiction Headache $O$ Curr Treat Res 1992;3:45-50.

8 Kischka U, Ettlin TM, Heim S, Schmid G. Cerebral symptoms following whiplash injury. Eur Neurol 1991;31:136-40

9 Davis SJ, Teresi LM, Bradley WG Jr, Ziemba MA, Bloze AE. Cervical spine hyperextension injuries: MR findings. Radiology sion injuries: MR

10 Byrn C, Olsson I, Falkheden L, et al. Subcutaneous sterile water injections for chronic neck and shoulder pain following whiplash injuries. Lancet 1993;341:449-52.

\section{Car toll neuropathy}

The "piriformis muscle syndrome" is an entrapment syndrome of the sciatic nerve as it passes through the greater sciatic notch. Buttock tenderness, leg pain aggravated after internal rotation of the flexed limb, and a limp are the main features of this clinical syndrome. Sciatica is reproduced upon deep digital palpation. Common causes include pelvic or buttock trauma, pelvic surgery, mass lesions, and piriformis muscle anomalies. I have seen a patient who developed the piriformis muscle syndrome after a car trip through three European countries with highway charges.

This 70-year-old, previously healthy man returned to Germany from a holiday trip to Portugal with his car. In order to pay the car toll in Spain and France he had prepared small change in the necessary currencies and put it in his left back trouser pocket. He made the 18-hour trip in one day. On the next day he complained of pain in his left buttock down the posterior thigh, which became worse during the days that followed. The pain increased with walking but not with coughing. After the exclusion of a lumbar disc prolapse by spinal CT and persisting pain, despite application of several analgesics and nonsteroidal antirheumatics, the patient was referred for neurological evaluation six weeks after the car trip.

On examination, he showed a limp, holding his left leg in mild external rotation. Both passive internal rotation and forced adduction of the affected limb by the examiner caused pain. There was piriformis tenderness on deep digital palpation. The straight-leg-rising test was negative. There were no pareses and normal reflexes, but mild atrophy of the left gluteal muscles was apparent. Although routine electroneurographic studies of the sciatic nerve and its branches revealed normal results, there was a delay of the H-reflex on the left side when the test was performed after internal rotation of the limb. Pelvic CT excluded a mass lesion of the piriformis muscle. The patient was successfully treated by local injections with lidocaine and steroids in combination with physical therapy.

The "piriformis muscle syndrome" has been reported after prolonged sitting on a toilet seat" and as "credit-card-wallet sciatica". ${ }^{2}$ In this patient, the electrophysiologically documented syndrome $\mathrm{e}^{3}$ was caused by the coins prepared for the car toll on a trans-European car trip.

$$
\begin{array}{r}
\text { PETER BERLIT } \\
\text { Alfried Krupp Clinic, Essen, } \\
\text { Germany } 45117
\end{array}
$$

1 Taxay EP. Toilet-seat neuropathy. $N$ Engl $f$ Med 1969;280:1484.

2 Lutz EG. Credit-card-wallet sciatica. $\mathscr{f} A M A$ 1978;240:738.

3 Fishman LM, Zybert PA. Electrophysiologic evidence of piriformis syndrome. Arch Phys Med Rehabil 1992;73:359-64.

"Familial paroxysmal tremor": an essential tremor variant?

The presence of symmetrical postural tremor in the hands, affecting several members of a family (familial essential tremor), is a common movement disorder, of which the clinical features are well known. ${ }^{1-3}$ We describe a patient with paroxysmal postural tremor in both hands. His mother and two of his brothers had a similar clinical picture.

A 24-year-old man, who was a good player of classic guitar, was referred to our hospital because of episodic hand tremor. $\mathrm{He}$ had no previous neurological diseases. Since the age of 18 , he had had episodes of symmetrical postural tremor limited to the hands lasting from 10 to 60 minutes, occurring once every three to six weeks. These episodes began abruptly and ended gradually. Tremor was not associated with dystonic postures or movements. Neurological examination was normal except for the presence of the postural hand tremor during the episodes. The intensity of the tremor was variable for each episode, but occasionally it interfered with writing, eating, drinking, or playing the guitar. We were unable to find any precipitating factor such as ethanol, other drugs or toxic substances, tiredness, anxiety, exercise, occupation, fasting, etc. All routine investigations, including thyroid hormones, plasma catecholamines during one episode, EEG, and cranial CT were normal. Electromyographical recording when his arms were outstretched showed a synchronous 9-10 $\mathrm{Hz}$ tremor. Because the episodes of tremor were infrequent and mild, we did not treat him with drugs.

Two of his four brothers, aged 21 and 22 years, have an episodic tremor with the same characteristics, although this is less severe and the frequency of presentation of episodes is lower, occurring since the age of 20. His mother, aged 50 years, began with an identical clinical picture in late adolescence, but the frequency and intensity of the tremor episodes decreased with the passage of time. Finally she developed, at age 48, a typical essential tremor in the hands, which responded to propranolol.

The movement disorder of our patient was a postural tremor affecting both hands. The clinical and electromyographical features of this tremor were indistinguishable from those of essential tremor, although the paroxysmal presentation of the tremor is exceptional. To our knowledge, only three cases of paroxysmal tremor have been described: two patients with paroxysmal head tremor associated with cervical dystonia $^{4}$ and one child with "rubral-like" tremor in arms and legs, and orofacial dyskinesia associated with a biopterin-synthesis defect. ${ }^{5}$ We propose this "familial paroxysmal tremor" as a possible variant of essential tremor.

$$
\begin{array}{r}
\text { E GARCIÁ-ALBEA } \\
\text { F J JIMÉNEZ- JIMÉNEZ } \\
\text { L AYUSO-PERALTA, } \\
\text { J TEJEIRO } \\
\text { F CABRERA-VALDIVIA } \\
\text { A VAQUERO } \\
\text { Section of Neurology, } \\
\text { Hospital Universitario "Principe de Asturias", } \\
\text { Carretera de Meco S/N, } \\
\text { E-28805 Alcalá de Henares, } \\
\text { Madrid, Spain }
\end{array}
$$

Correspondence to: Dr Garcia-Albea.

1 Martinelli P. Different clinical features of essential tremor: a 200 patient study. Acta Neurol Scand 1987;75:106-11.

2 Weiner WJ, Lang AE. Tremor. In: Weine WJ, Lang AE, eds. Movement disorders: a comprehensive survey. Mount Kisco, NY: Futura, 1989; 221-56.

3 Lou HS, Jankovic J. Essential tremor: clinical correlates in 350 patients. Neurology 1991; 41:234-8.

4 Hughes AJ, Lees AJ, Marsden CD. Paroxysmal dystonic head tremor. Mov Disord 1991;6:85-6.

5 Factor SA, Coni RJ, Cowger M, Rosenblum EL. Paroxysmal tremor and orofacial dyskinesia secondary to a biopterin synthesis defect. Neurology 1991;41:930-2. 